\title{
Evaluation of soluble microbial products and aromatic amines accumulation during a combined anaerobic/aerobic treatment of a model azo dye
}

\author{
B.E.L. Baêta ${ }^{a}$, D.R.S. Lima ${ }^{\mathrm{b}}$, S.Q. Silva ${ }^{\mathrm{c}}$, S.F. Aquino ${ }^{\mathrm{a}, *}$ \\ ${ }^{a}$ Chemistry Department, Federal University of Ouro Preto, Ouro Preto, Brazil \\ ${ }^{\mathrm{b}}$ Post-Graduate Programme in Environmental Engineering, Federal University of Ouro Preto, Ouro Preto, Brazil \\ ${ }^{\mathrm{C}}$ Biological Sciences Department, Federal University of Ouro Preto, Ouro Preto, Brazil
}

\section{H I G H L I G H T S}

- Anaerobic-aerobic combined system was efficient in removing aromatic amines, VFA, SMP and color from azo dye effluents.

- PAC played a key role in reducing SMP accumulation in anaerobic environment.

- Yeast extract, a cheap source of redox mediators, enhance color removal in the anaerobic reactor.

- The aerobic post-treatment unit completely removed the aromatic amines and VFA from the anaerobic effluent.

\section{A R T I C L E I N F O}

\section{Article history:}

Received 20 March 2014

Received in revised form 14 August 2014

Accepted 17 August 2014

Available online 27 August 2014

\section{Keywords:}

Azo dye degradation

Anaerobic digestion

Soluble microbial products

Powdered activated carbon

\begin{abstract}
A B S T R A C T
The current work have investigated the accumulation of soluble microbial products (SMP) and aromatic amines in anaerobic reactors followed by aerobic reactors (Ar1 or Ar2) during the azo dye Remazol Golden Yellow RNL (RGYRNL) degradation. One anaerobic reactor (An2) contained powdered activated carbon (PAC) in its interior, while another one (An1) was used as control. The results have shown the efficiency of COD and color removal in the combined system An1/Ar1 was higher than 70\%, while in the An2/ Ar2 system the COD and color removal was above $85 \%$ and $90 \%$, respectively, in all three operational phases. The aerobic reactors were capable of removing most of the residual organic matter, volatile fatty acid (VFA) and aromatic amines, generated during the anaerobic step, and the presence of PAC inside reactor An2 ensured higher operational stability since it minimized the toxic effects caused by anaerobic degradation byproducts. The presence of PAC contributed to reduce SMP accumulation in phases 2 $\left(\mathrm{COD}_{\mathrm{SMP}}=32.40 \mathrm{mg} / \mathrm{L}\right)$ and $3\left(\mathrm{COD}_{\mathrm{SMP}}=21.61 \mathrm{mg} / \mathrm{L}\right)$ and enhanced the effluent quality .
\end{abstract}

(c) 2014 Elsevier B.V. All rights reserved.

\section{Introduction}

Nowadays, azo dyes represent the larger class of synthetic dyes produced worldwide (about 70\%) and its high production might be associated with its use by different industrial sectors such as textile, food, paper and cosmetics [1]. The discharge of colorful effluents in the environment, even those containing low concentration of soluble dyes, is not just an aesthetic issue, but also an environmental trouble.

The discharge of colorful wastewater negatively impacts aquatic eco-systems, worsens water quality and inhibits aquatic photosynthesis. Such troubles are related to the depletion of dissolved

\footnotetext{
* Corresponding author. Tel.: +55 (031) 35591229.

E-mail address: sergio@iceb.ufop.br (S.F. Aquino).
}

oxygen, $\mathrm{pH}$ changes, and incorporation of recalcitrant substances in the environment. Some studies have also pointed out that azo dyes and their byproducts (aromatic amines) can be carcinogen and mutagen to many species [2].

In view of the complexity of effluents that contain azo dyes, different kinds of treatment have been used, such as (electro) coagulation/flocculation [3,4] and advanced oxidation [5], including photocatalysis [6]. The main disadvantage of these technologies is their high cost, in addition to the fact they demand a greater amount of energy [7]. In some cases, such treatments can generate toxic byproducts that are not easily disposed of [8]. Due to such reasons, some authors state that biological processes are the most economically feasible technology to efficiently degrade industrial organic compounds such as the azo dyes and their byproducts [9-12]. 
Amidst the biological processes, the conventional activated sludge system is widely used to treat textile wastewaters. Despite being very efficient in removing the organic load it exhibits relatively low discoloration rates. Such obstacle is explained by the fact dissolved oxygen is a preferred electron acceptor when compared to azo dyes [13]. On the other hand, azo dye discoloration is more easily achieved in anaerobic systems which promote its reductive degradation. Nonetheless, when effluents contain other electron acceptors with higher reductive potentials, such as sulfates $\left(\mathrm{SO}_{4}^{-2}\right)$, nitrates $\left(\mathrm{NO}_{3}^{-}\right)$and nitrites $\left(\mathrm{NO}_{2}^{-}\right)$, the azo dye anaerobic degradation can be hampered [14].

According to some authors, biological azo dye degradation happens in two stages [15]. The first step is the reductive cleavage of the azo bond $(-\mathrm{N}=\mathrm{N}-$ ), which normally leads to color reduction; and the subsequent degradation of the produced aromatic amines, which is more easily accomplished in aerobic environments. Therefore, an inconvenient caused by azo dye reductive degradation in anaerobic reactors is the accumulation of recalcitrant byproducts. In many cases these compounds exhibit certain toxicity to the anaerobic microbial consortium, thus leading to operational limitations in such systems [16]. In face of the limitations observed in both aerobic (low color removal) and anaerobic (difficulty in aromatic amines mineralization) reactors, many authors suggest that a feasible alternative to the treatment of colorful effluents containing different types of azo dyes is the combination of both processes [16-18].

Due to the aforementioned, the current work aimed to evaluate the performance of an anaerobic/aerobic treatment system comprised of anaerobic reactors (with and without powdered activated carbon [PAC] in its interior) followed by aerobic reactors. The treatment system was fed with a model azo dye (Remazol Golden Yellow RNL - RGY-RNL) solution. Particularly, this study focused

Table 1

Characteristics of the powdered activated carbon (PAC).

\begin{tabular}{lllll}
\hline $\begin{array}{l}\text { Apparently } \\
\text { density } \\
\left(\mathrm{g} / \mathrm{cm}^{3}\right)\end{array}$ & $\begin{array}{l}\text { Specific } \\
\text { surface area } \\
\left(\mathrm{m}^{2} / \mathrm{g}\right)\end{array}$ & $\begin{array}{l}\text { Total pore } \\
\text { volume } \\
\left(\mathrm{cm}^{3} / \mathrm{g}\right)\end{array}$ & $\begin{array}{l}\text { Maximum } \\
\text { pore } \\
\text { diameter }(\AA)\end{array}$ & $\begin{array}{l}\text { Average } \\
\text { pore } \\
\text { diameter }(\AA)\end{array}$ \\
\hline $0.20-0.75$ & 452.589 & 0.28940 & 1164.70 & 12.79 \\
\hline
\end{tabular}

Raw material: wood of Pinus spp. on the accumulation of soluble microbial products (SMP) and other byproducts (aromatic amines and VFA) in the combined treatment system.

\section{Materials and methods}

\subsection{Reactors configuration}

The study was performed using two batch anaerobic reactors named An1 (Control, without PAC) and An2 (Operated with $4 \mathrm{~g} / \mathrm{L}$ of PAC in its interior added only once during all operational phases). The PAC used inside the An2 reactor originated from pines wood and was manufactured by Carbon Solution ${ }^{\circledR}$ and some characteristics can be seen in Table 1.

Both anaerobic reactors (An1 and An2) were built out of pipe joints and polyvinyl chloride connections (PVC), so that both had the same working volume of 3.25 L. As it can be seen in Fig. 1, effluents from An1 and An2 were submitted to aerobic post-treatment in the reactors Ar1 and Ar2. Such reactors were built out of glass, and had a working volume of $3.5 \mathrm{~L}$. The mixture and the aeration in reactors Ar1 and Ar2 were ensured by compressed air pumps. The effluents of reactors $\operatorname{Ar} 1$ and $\operatorname{Ar} 2$ flowed to the settler units (Fig. 1) that were also built out of PVC and had a working volume of $3.5 \mathrm{~L}$.

\subsection{Operational conditions}

Throughout the three operational phases the An1/Ar1 and An2/ Ar2 systems were fed with a dye solution containing micro and macro nutrients. Micro and macro nutrient concentrations were defined in order to maintain the proportion of COD:N:P close to that considered as ideal (350:5:1) to anaerobic process [19]. Table 2 shows the composition of the feeding solution used in each operational phase.

An1/Ar1 and An2/Ar2 bench reactors were simultaneously fed under the same operational conditions during all three operational phases. Anaerobic reactors (An1 and An2) operated with a hydraulic retention time (HRT) of $24 \mathrm{~h}$ and controlled temperature of $35^{\circ} \mathrm{C}$. The $\mathrm{pH}$ inside these reactors was kept between 6.5 and 7.5 by adding $\mathrm{Na}_{2} \mathrm{CO}_{3} 0.1 \mathrm{M}$ buffer solution. On the other hand, the aerobic reactors (Ar1 and Ar2) operated with an HRT of approximately $28 \mathrm{~h}$, at room temperature, $\mathrm{pH}$ between 6.8 and 7.2; and

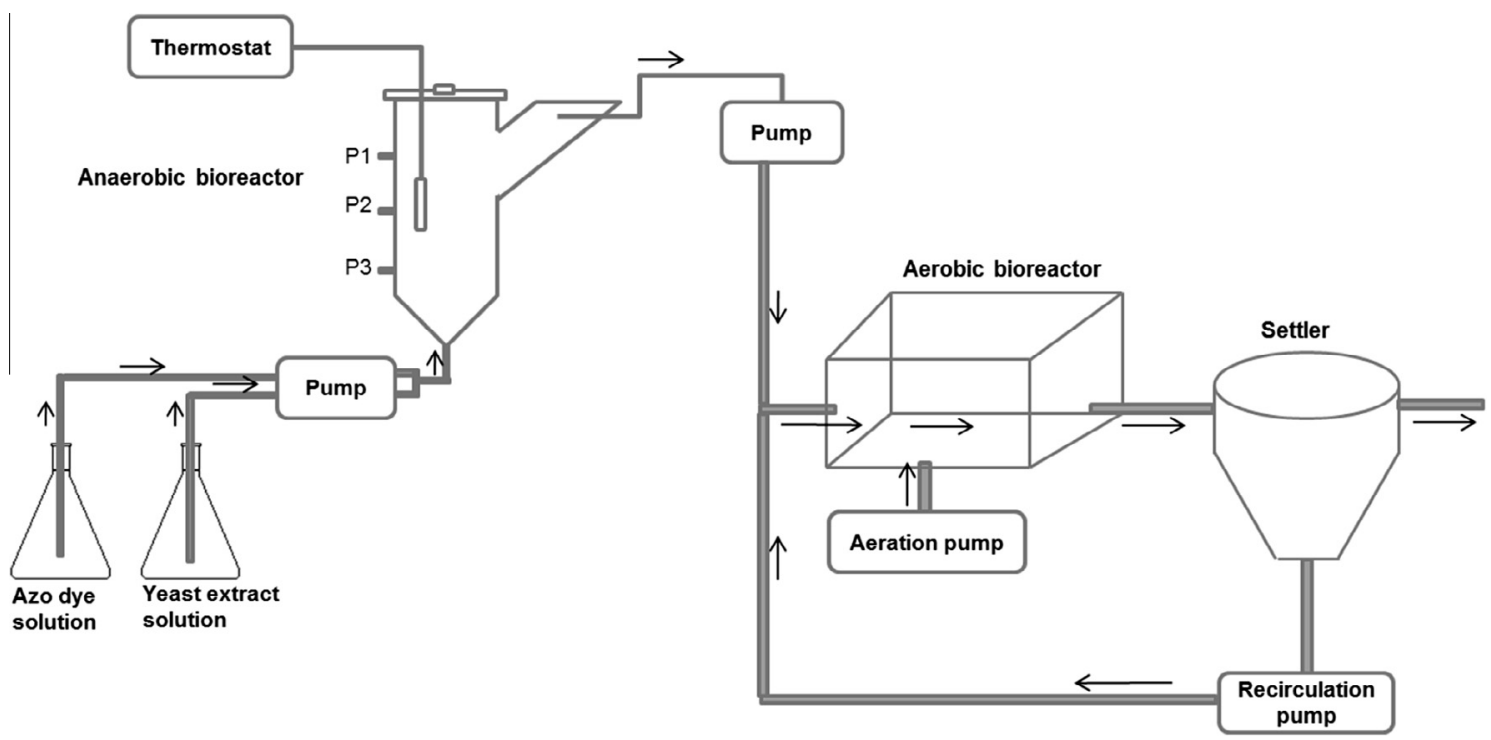

Fig. 1. Schematic of the bench scale combined anaerobic-aerobic (An-Ar) treatment system. 
Table 2

Composition of the feeding solution in different operational phases.

\begin{tabular}{|c|c|c|c|c|c|}
\hline Phase & Azo dye $^{a}(\mathrm{mg} / \mathrm{L})$ & Yeast extract $^{\mathrm{b}}(\mathrm{mg} / \mathrm{L})$ & Glucose $^{\mathrm{c}}(\mathrm{mg} / \mathrm{L})$ & COD influent $^{\mathrm{d}}(\mathrm{mg} / \mathrm{L})$ & Comments \\
\hline 1 & No & No & Yes (500) & 509 & Acclimation period \\
\hline 2 & Yes (50) & No & Yes (500) & 522 & $\begin{array}{l}\text { Azo dye degradation in the absence of redox mediator } \\
\text { and with an extra source of carbon }\end{array}$ \\
\hline 3 & Yes (50) & Yes (500) & No & 544 & $\begin{array}{l}\text { Azo dye degradation in the presence of yeast extract, a } \\
\text { cheap source of carbon and redox mediator }\end{array}$ \\
\hline
\end{tabular}

a The model azo dye used was Remazol Golden Yellow RNL (RGYRNL).

b Used as source of riboflavin, a soluble redox mediator.

c Used as source of carbon and energy.

d Median value.

dissolved oxygen concentration (DO) between 2.0 and $3.5 \mathrm{mg} / \mathrm{L}$. The difference between $\operatorname{Ar} 1$ and $\operatorname{Ar} 2$ are the fact that Ar2 receives an effluent from an anaerobic reactor (An2) that contains PAC inside it.

During the operation of An/Ar systems, it was used a secondary settler (Fig. 1) in order to separate the biologically active biomass fraction coming from the aerobic reactor. Such biomass was recirculated from the bottom of the secondary settler into the aerobic reactors. Some fundamental parameters regarding the aerobic reactors functioning - calculated according to mean values observed in each operational phase - are presented in Table 3.

An 1 and An2 reactors were incubated with $0.8 \mathrm{~L}$ of anaerobic sludge having a volatile suspended solids (VSS) concentration of approximately $10 \mathrm{~g} / \mathrm{L}$. On the other hand, the $\operatorname{Ar} 1$ and $\operatorname{Ar} 2$ reactors were incubated with $1.5 \mathrm{~L}$ of activated sludge with volatile suspended solids (VSS) concentration of $\sim 8 \mathrm{~g} / \mathrm{L}$. The anaerobic and aerobic sludge were taken from UASB reactors and activated sludge systems, respectively, operated at demo (UASB) or full scale (activated sludge) and fed with raw sewage.

\subsection{Analytical methods}

Color removal and degradation of Remazol Golden Yellow RNL were monitored in the wavelength of higher dye absorption $\left(\lambda_{\max }=410 \mathrm{~nm}\right)$ in a HP 8453 UV-visible spectrophotometer, by means of an external calibration curve made with the model azo dye. COD measurements were performed according to the closed reflux colorimetric method, as described in the Standard Methods for the Examination of Water and Wastewater (APHA, 2010). All samples were previously centrifuged at $3.600 \mathrm{rpm}$ for $20 \mathrm{~min}$ (Fanem Excelsa II $206 \mathrm{BL}$ ) in order to remove suspended solids. Thus, all data presented here were obtained with the supernatant of the centrifuged samples.

The analysis of seven (formic, acetic, propionic, butyric, isobutyric, valeric, isovaleric) volatile fatty acids (VFA) was accomplished by using a high performance liquid chromatography

Table 3

Operational conditions observed in the aerobic reactors calculated according to mean values observed in each operational phase.

\begin{tabular}{lllll}
\hline Reactors & Parameters & Phase 1 & Phase 2 & Phase 3 \\
\hline Ar1 & $R^{\text {a }}$ & 0.82 & 0.96 & 0.89 \\
& MLVSS $^{\text {b }}(\mathrm{mg} / \mathrm{L})$ & 6300 & 7815 & 8875 \\
& RLVSS $^{\mathrm{c}}(\mathrm{mg} / \mathrm{L})$ & 7640 & 8630 & 9527 \\
& Sludge age $^{\mathrm{d}}(\mathrm{d})$ & 3.84 & 4.53 & 5.03 \\
\multirow{4}{*}{ Ar2 } & $R^{\mathrm{a}}$ & 0.85 & 0.91 & 0.93 \\
& MLVSS $^{\mathrm{b}}(\mathrm{mg} / \mathrm{L})$ & 6728 & 8215 & 9825 \\
& RLVSS $^{\mathrm{c}}(\mathrm{mg} / \mathrm{L})$ & 7987 & 9376 & 10287 \\
& Sludge age $(\mathrm{d})$ & 4.23 & 4.75 & 5.18
\end{tabular}

\footnotetext{
a Recycle ratio.

b Mixed liquor volatile suspended solids.

c Recirculation liquor volatile suspended solids.

d Estimated as $\mathrm{SA}=\frac{\left(\mathrm{MLVSS} \times V_{r}\right)}{\left(Q_{\text {discharge }} \times \mathrm{RLSSV}\right)+\left(Q_{\mathrm{ef}} \times \mathrm{VSS}_{\mathrm{ef}}\right)}[20]$.
}

(HPLC) system equipped with a diode array detector and setting the wavelength $(\lambda)$ at $210 \mathrm{~nm}$. The chromatographic separation was performed in an Aminex HPX-874 (Bio-Rad ${ }^{\circledR}$ ) ion exchange column at $55^{\circ} \mathrm{C}$, using a $0.01 \mathrm{M}$ sulfuric acid solution as mobile phase under isocratic flow of $0.6 \mathrm{~mL} / \mathrm{min}$ and the volume injected in the HPLC was $10 \mu \mathrm{L}$. Samples were previously filtered in cellulose acetate membranes $(0.45 \mu \mathrm{m})$ and the method was properly validated by Mesquita [21]. VFA concentrations were used to estimate their contribution to the dissolved COD according to Eq. (1):

$$
\begin{aligned}
\operatorname{COD}_{(\mathrm{VFA})}= & 0.35 \times[\text { formate }]+1.07 \times[\text { acetate }]+1.51 \\
& \times[\text { propionate }]+1.82 \times[\text { butyrate }+ \text { isoutyrate }] \\
& +2.04 \times[\text { valerate }+ \text { isovalerate }]
\end{aligned}
$$

The identification and quantification of aromatic amines formed during anaerobic azo dye degradation in samples from inside the An1 and An2 reactors, as well as in anaerobic and aerobic effluents, were done according to the same methodology applied to VFA identification. According to Pinheiro et al. [22] the degradation of azo dyes containing sulfonic acid groups, such as the model dye used in this study, generates as byproducts aromatic amines with sulfonic groups, such as the sulfanilic acid - which exhibits high absorption at $197 \mathrm{~nm}$. Thereby, the concentration of sulfanilic acid was estimated by external calibration using sulfanilic acid standards ( 0.5 up to $30 \mathrm{mg} / \mathrm{L}$ ), which yielded a calibration curve with good linear adjustment $\left(R^{2}=0.997\right)$.

The assessment of soluble microbial products ( $\left.\mathrm{COD}_{\mathrm{SMP}}\right)$ accumulation inside the anaerobic (An1 and An2) and aerobic (Ar1 and $\mathrm{Ar} 2$ ) reactors was achieved by estimating the amount of COD due to volatile fatty acids, residual RGYRNL and its degradation byproducts (expressed as sulfanilic acid), according to Eq. (2):

$\mathrm{COD}_{\mathrm{SMP}}=\mathrm{COD}_{\text {soluble }}-\mathrm{COD}_{\mathrm{VFA}}-\mathrm{COD}_{\text {residual azo dye }}-\mathrm{COD}_{\text {aromatic amines }}$

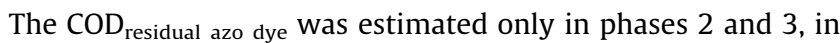
which the reactors An1 and An2 were fed with the model azo dye. For this the median color removal efficiency observed in each reactor was calculated and the residual RGYRNL concentration was estimated by means of an external calibration curve. The reaction stoichiometry for complete oxidation of the azo dye (1.64 gCOD/ gRGYRNL) was then used to estimate the theoretical $\mathrm{COD}_{\text {residual azo dye }}$ in each phase.

In order to estimate the amount of $\mathrm{COD}_{\text {aromatic amines }}$ it was considered that the amines generated by the reduction of the model azo dye were sulfanilic acid (SA) derivatives. Such consideration is supported by the observation that there were few peaks with retention times distinct from that of sulfanilic acid in the HPLC chromatograms. Therefore, in order to calculate the amount of $\mathrm{COD}_{\text {aromatic amines }}$ the concentration of sulfanilic acid was initially determined and then the median concentration of such intermediate was used to estimate its contribution to the soluble COD. This 
was done by using the stoichiometric coefficient for sulfanilic acid complete oxidation (2.26 gCOD/g SA).

\subsection{Statistical analysis}

In order to verify whether the differences observed between the An1/Ar1 and An2/Ar2 were significant, statistical tests were employed by means of the software Statistica ${ }^{\circledR}$. The Shapiro-Wilk test was used to confirm that the results did not follow a normal distribution, and then non-parametric tests (Kruskal-Wallis ANOVA, Student-Newman and Mann-Whitney) were applied. A $p$-value lower than 0.05 was adopted for rejecting the null hypothesis $\left(H_{\mathrm{o}}\right)$.

\section{Results and discussion}

\subsection{COD removal in the combined treatment systems}

Data of COD removal from the combined systems An1/Ar1 and An2/Ar2 are shown in Fig. 2. It is possible to verify the efficiency values for organic matter removal in the anaerobic reactor An2 (operated with PAC within its interior) was higher in all operational phases $(53.3 \%$ in phase $1,76.2 \%$ in phase 2 and $83.0 \%$ in phase 3 ), when compared to the values obtained in the control reactor An1 (52.3\% in phase 1, 49.0\% in phase 2 and 68.2 in phase $3)$, except in phase 1 when no statistical significant differences $(p$-value $>0.05)$ were observed. Such results evidence the contribution of PAC in the removal of organic matter in anaerobic systems, as previously demonstrated [12].

Baêta et al. [12] employed membrane bioreactors to treat textile effluents and observed that the presence of PAC inside the anaerobic reactor favored the adaptation of anaerobic microorganisms, minimized stress factors and led to higher removal efficiencies. This is due to PAC's capacity of adsorbing toxic components, such as aromatic amines or VFA, which thermodynamically limits the bacterial conversion of propionate, (iso)butyrate and (iso)valerate into acetate. According to Aquino and Chernicharo [23] the absence of stressing factors in anaerobic reactors results in lower accumulation of VFA and, consequently, in higher COD removal, due to the higher conversion of acetic acid into methane.

Fig. 2 also shows that the aerobic reactors Ar1 and Ar2 removed the major part of the organic matter recalcitrant to anaerobic systems, mainly - as it will be discussed later - the byproducts generated from anaerobic degradation of model azo dye (aromatic amines) and intermediate VFAs. The lower values of organic matter removal observed in phase 1 for both reactors, when compared to other phases, might be associated with biomass adaptation. However, even with the observed lower values, it is possible to infer that the presence of PAC inside reactor An2, which precedes reactor Ar2, positively influenced aerobic biomass adaptation time, resulting in better performance of reactor Ar2.

Throughout phase 1 (without dye) it was observed a significant difference $(p$-value $<0.05)$ in the removal of COD between reactors Ar1 (38.3\%) and Ar2 (71.2\%), indicating that the microorganisms found in reactor Ar2 underwent better adaptation during acclimation phase. Such results also indicate that the use of PAC within the anaerobic reactor withheld toxic or recalcitrant compounds to aerobic microorganisms.

During phase 2 there was an increase in the COD removal efficiency of $54.2 \%$ for $\operatorname{Ar} 1$ and $21.5 \%$ for Ar2. The lower increase observed for reactor Ar 2 might be related to the reduced concentration of soluble COD flowing into the system, once the major part of soluble organic matter that should reach reactor Ar2 is removed in the An2 system, due to the effective action of PAC in promoting better microbial adaptation.

In phase 3 it was observed a decrease of approximately 32\% in the efficiency of COD removal for reactor Ar1 and 15\% for reactor Ar2 (in relation to phase 2), and such behavior can be explained by the presence of yeast extract. The greater complexity of the organic compounds found in the extract (e.g. proteins, lipoproteins, lipids), along with the stronger organic load applied to the system seemed to have led to higher residual COD residual from the anaerobic reactors.

Nevertheless, Fig. 2 shows that the aerobic reactors Ar1 and Ar2 significantly increased the total efficiency of COD removal in the system An1/Ar1 and An2/Ar2 in all operational phases. Such results were expected, once a higher amount of carbon is required by aerobic microorganisms due their higher microbial growth rates.

Fig. 3 shows the accumulation of VFA (expressed as COD) inside anaerobic reactors An1 and An2. The values of $\mathrm{COD}_{\mathrm{VFA}}$ in the aerobic reactors were not shown because the VFA concentration was lower than the method's limit of detection (LOD). Such results indicate that all residual soluble COD effluent from the aerobic phase is due to SMPs produced in anaerobe and aerobic reactors.

Fig. 3 shows that the concentrations of $C_{\mathrm{VO}} \mathrm{D}_{\mathrm{VFA}}$ inside reactor An2 (with PAC) in all operational phases were statistically lower $(p$-value $<0.05)$ than the values found for reactor An1, indicating that inside An2 there was a significantly higher removal rate,
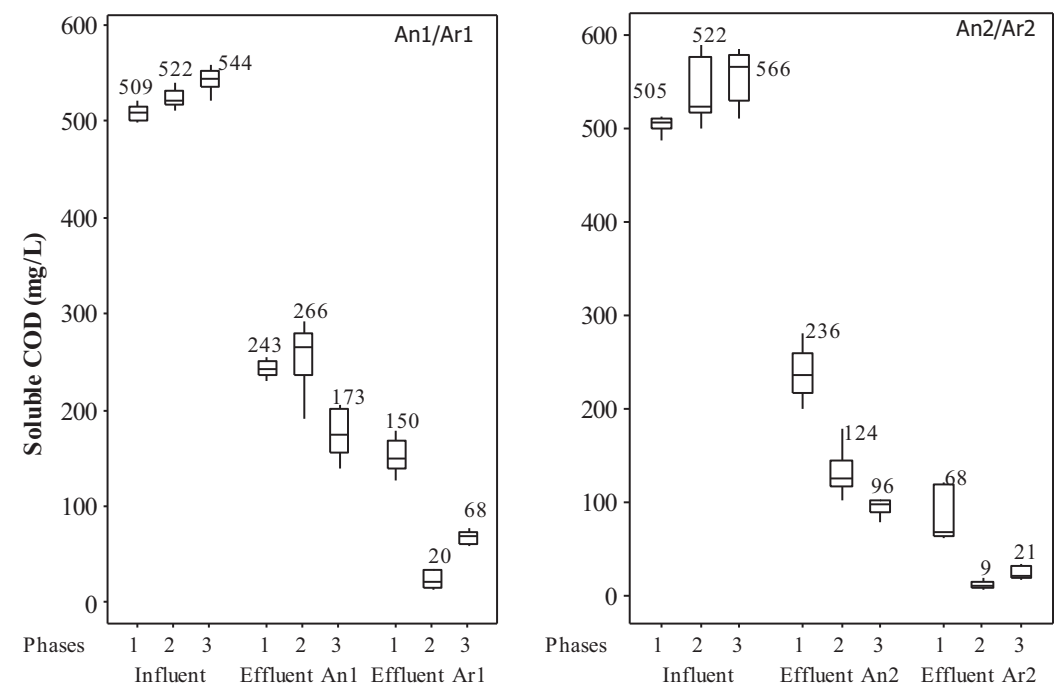

Fig. 2. Dissolved organic matter (soluble COD) in influent and effluent from An1/Ar1 (control) and An2/Ar2 (with PAC) combined treatment systems. 


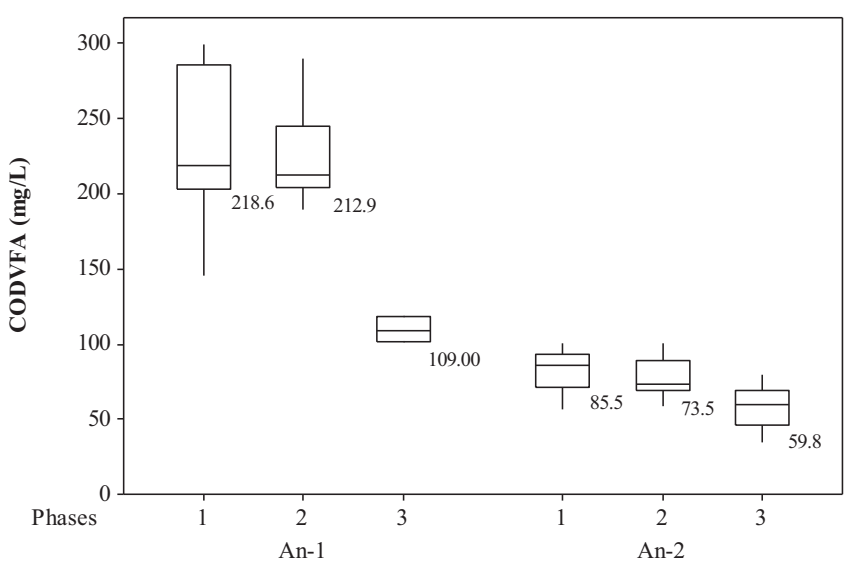

Fig. 3. Changes in soluble $\mathrm{COD}_{\mathrm{VFA}}$ inside the anaerobic reactors.

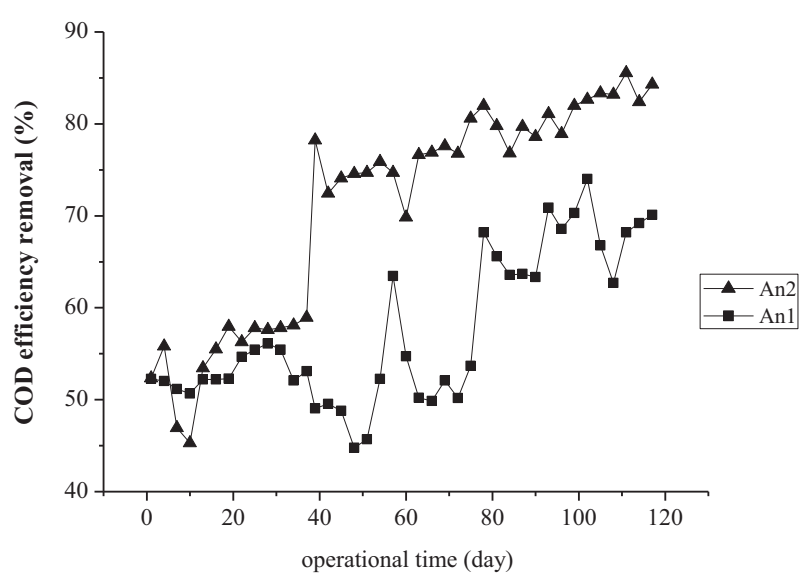

Fig. 4. COD removal efficiency for An2 (with PAC) during the operational time.

probably motivated by better adaptation and biomass growth conditions.

The best adaptation observed in the system comprising PAC, derives from its capacity to adsorb toxic substances (e.g. aromatic amines) and VFA. The adsorption of such compounds minimizes

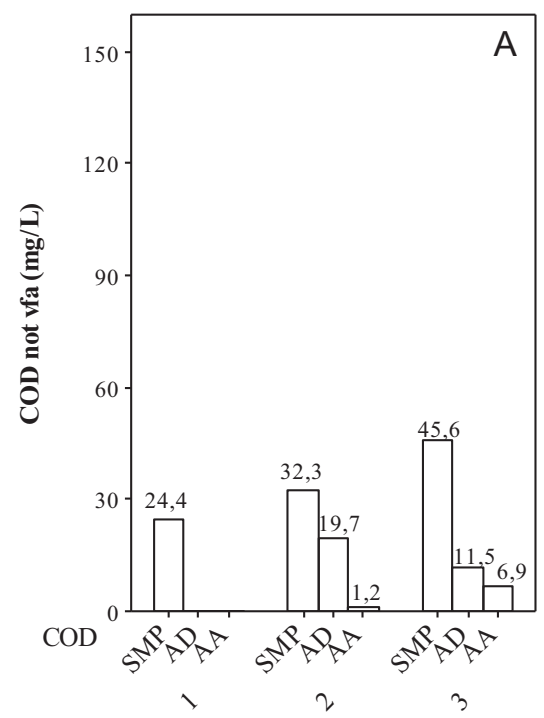

the thermodynamic inhibition of some conversion routes (e.g. acetate to propionate), besides keeping a proper balance amongst acidogenesis and methanogenesis. Baêta et al. [24] showed that PAC had a great capacity to adsorb some intermediate VFA such as acetic $\left(Q_{\max }=5.80 \mathrm{mg} / \mathrm{g}\right)$, butyric $\left(Q_{\max }=5.19 \mathrm{mg} / \mathrm{g}\right)$ and propionic $\left(Q_{\max }=0.096 \mathrm{mg} / \mathrm{g}\right)$ acids, which led to lower VFA accumulation and better submerged anaerobic membrane bioreactor performance.

Based on the values of $Q_{\max }$ and Eq. (1) it was possible to estimate that the PAC added inside the reactor at the beginning of An2 operation would be able to retain approximately $67 \mathrm{mg} / \mathrm{L}$ of $\mathrm{COD}_{\mathrm{VFA}}$. This corroborates the hypothesis that PAC might have played an important role in the reactor thermodynamics by minimizing VFA concentration in the supernatant and favoring the activity of acetogenic microorganisms.

Fig. 4 shows that there was no trend in COD removal reduction throughout the operational time. For An2 (with PAC) the COD removal efficiency remained pretty stable along the operation, indicating that PAC's adsorption sites were not saturated and, or that adsorption could not solely account for the COD removal. Fig. 4 data suggests that some adsorbed organics (e.g. dyes, aromatic amines and VFA) were metabolized by anaerobic microorganisms, which would continually free PAC's adsorption sites. It is not known whether microorganisms can uptake adsorbed molecules directly from the PAC surface or whether such molecules are desorbed by equilibrium shift as their concentrations are reduced in the bulk phase.

\subsection{Evaluation of $C O D_{S M P}$ accumulation in reactors $A n 1$ and An2}

Figs. 5 and 6 respectively show the mean concentration of SMP (as COD) and its normalized accumulation ( $\left.\mathrm{COD}_{\mathrm{SMP}} / \mathrm{gVSS}\right)$ in both anaerobic reactors An1 (control) and An2 (with PAC) throughout different operational phases. It is possible to see that during phase 1 , in which the reactors were fed with glucose as the only source of carbon and energy, the concentration of $\mathrm{COD}_{\mathrm{SMP}}$ inside reactor An1 and the ratio $\mathrm{COD}_{\mathrm{SMP}} / \mathrm{gVSS}$ was lower when compared to reactor An2. Such results are similar to those found by other authors such as Aquino et al. [25] who have also observed a higher concentration of $\mathrm{COD}_{\mathrm{SMP}}$ in an anaerobic reactor with submerged membrane (SAMBR) operated with PAC when compared with a SAMBR operated without PAC.

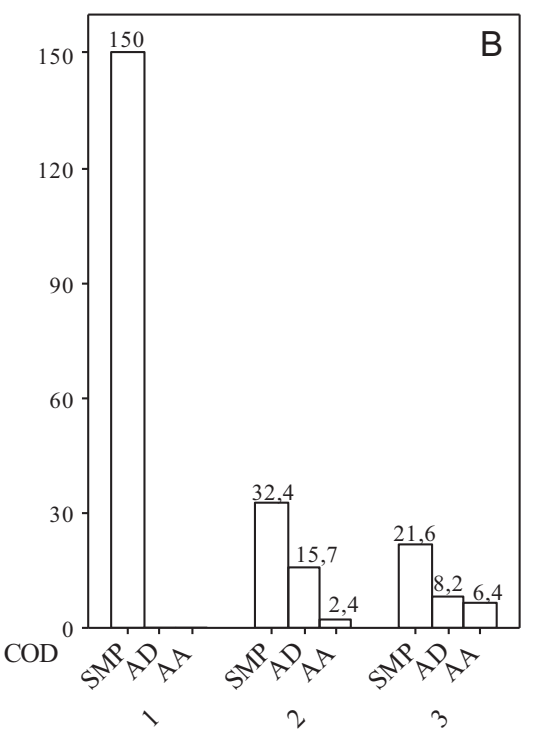

Fig. 5. Composition of COD in terms of soluble microbial products (SMP), azo dye (AD) and aromatic amines (AA) inside reactors An1 (A) and An2 (B). 


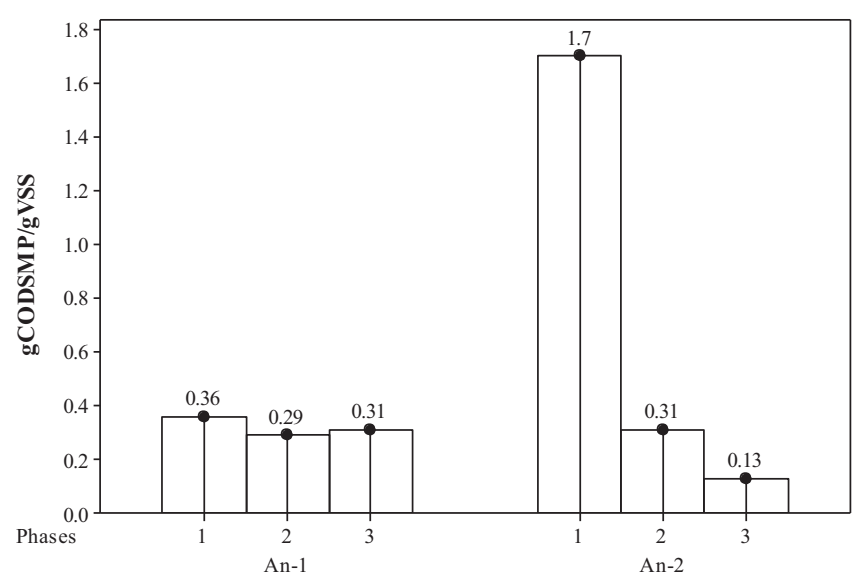

Fig. 6. Production of $\mathrm{COD}_{\mathrm{SMP}}$ inside the reactors $\mathrm{An} 1$ (A) and $\mathrm{An} 2$ (B) throughout the operational phases.

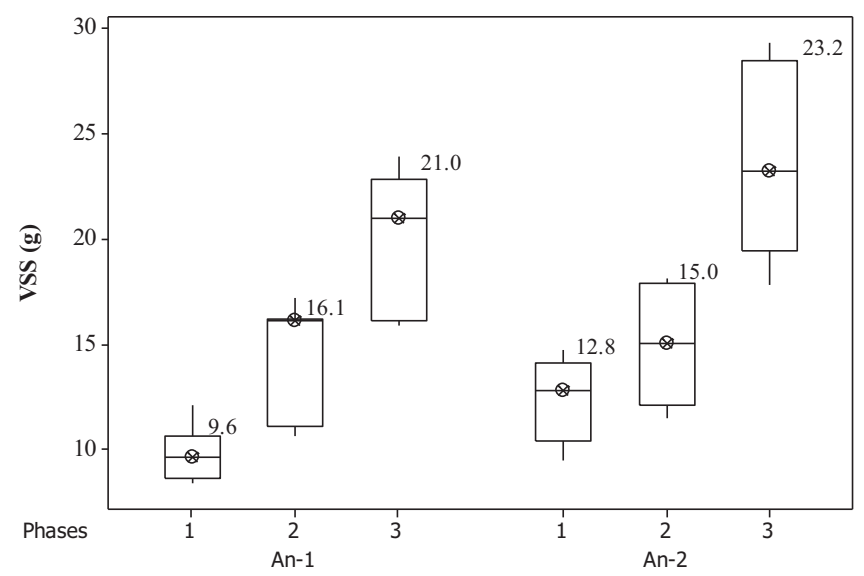

Fig. 7. VSS mass inside anaerobic reactors An1 and An2 throughout all the operational phases.

According to such study, both reactors were fed with an easily degradable substrate and a possible explanation for the higher SMP accumulation inside the reactor with PAC is related to the adsorbent's capability of acting as a means of support to microbial growth. The hypothesis here is that attached microbial growth would imply in the release of extracellular polymeric substances (EPS) which leads to the generation of SMP via its hydrolysis, thus contributing to the increase of soluble COD [26].

Another explanation for the higher $\mathrm{COD}_{\mathrm{SMP}}$ accumulation in the reactor with PAC (An2) during phase 1 is the greater amount of biomass inside it. According to Fig. 7, the VSS mass inside the reactor An2 (with PAC) was approximately 33\% larger than that observed inside the reactor An1 (without PAC). Additionally, Akram and Stuckey [27] observed a higher concentration of $\mathrm{COD}_{\mathrm{SMP}}$ in a SAMBR reactor operated with higher amounts of PAC $(3.4 \mathrm{~g} / \mathrm{L})$ and VSS $(16.116 \mathrm{mg} / \mathrm{L})$ and verified there was a straight relationship between the amount of SMP and the concentration of PAC and VSS.

The behavior of SMP accumulation (Fig. 5) in the anaerobic reactors during phase 2 shows that in the presence of PAC (An2) the $\mathrm{COD}_{\mathrm{SMP}}$ considerably decreased from phase 1 to phase 2 , reaching a median concentration of $32.4 \mathrm{mg} / \mathrm{L}$. On the other hand in the reactor without PAC $(A n 1)$ the concentration of $\mathrm{COD}_{\text {SMP }}$ increased from phase 1 to phase 2 , reaching the median value of $32.3 \mathrm{mg} / \mathrm{L}$, which is not statistically different ( $p$-value $>0.05$ ) from that observed in reactor An2. This indicates that the presence of dye and its byproducts in phase 2 induced SMP production in the reactor An1 (without PAC), and this was probably due to the higher toxicity experienced by the microorganisms, as already shown by other authors [28].

In phase 3 , an increase on color removal was observed in both reactors (Fig. 8) due to the presence of yeast extract, a source of the redox mediator riboflavin. The presence of yeast extract in the feed solution caused an increase (from 32.3 up to $45.6 \mathrm{mg} / \mathrm{L}$ ) in $\mathrm{COD}_{\mathrm{SMP}}$ in relation to phase 2 for reactor An 1 , which is possibly due to the higher toxicity caused by aromatic amines. Aquino and Stukey [28] also showed there was a higher SMP accumulation in the presence of toxic compounds due to enhanced cell lysis and EPS production and hydrolysis, and this reinforces the hypothesis that the increased SMP production in both reactors in phase 3 is related to the higher presence of aromatic amines accumulated following the anaerobic degradation of RGYRNL.

Indeed, it was observed, in this phase a higher median concentration of sulfanilic acid in the reactor An1 (Fig. 9), and some authors [29] attribute the higher toxicity of sulfonated azo dyes in anaerobic systems to the generation of this byproduct. As a
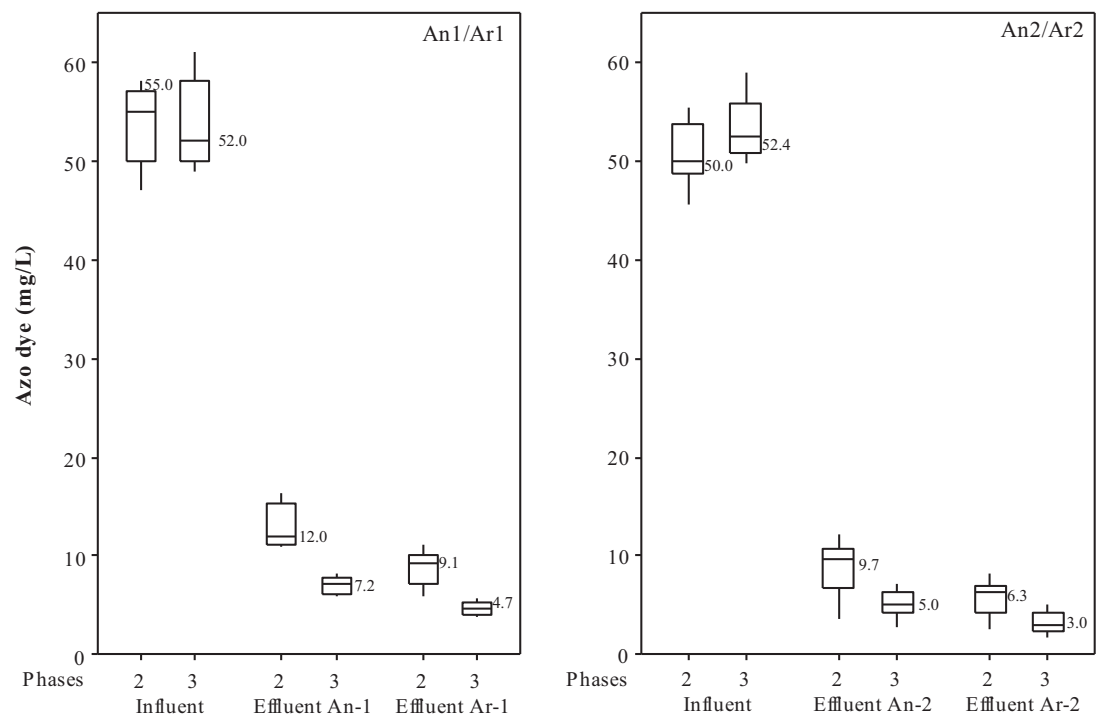

Fig. 8. Estimative of the azo dye RGYRNL concentration in the affluent and effluents from the An1/Ar1 and An2/Ar2 systems during phases 2 and 3. 


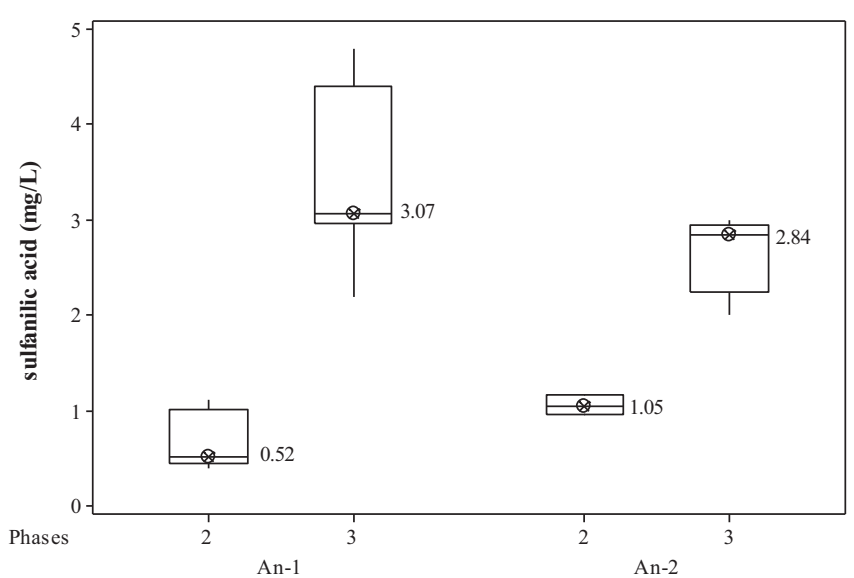

Fig. 9. Estimative of sulfanilic acid concentration inside reactors An1 and An2 during the phases in which the azo dye was fed to the reactors. result, the exposure of micro-organisms to high amounts of sulfanilic acid might have caused stressful conditions in the anaerobic reactors, mainly in An1 (without PAC), thereby enhancing cell lysis and EPS production $[28,30]$.

Such evidence is confirmed by Fig. 6 which shows there was an increase in the $\mathrm{COD}_{\mathrm{SMP}} / \mathrm{gVSS}$ ratio in reactor An1 from 0.29 (phase 2 ) to 0.31 (phase 3 ). In the reactor operated with PAC (An2), the same behavior was observed, however, as operation went on, there was a decrease in the COD $_{\mathrm{SMP}} / \mathrm{gVSS}$ ratio from phase $1(1.7 \mathrm{~g}$ $\left.\mathrm{COD}_{\mathrm{SMP}} / \mathrm{gSSV}\right)$ to phase $2\left(0.31 \mathrm{~g} \mathrm{COD}_{\mathrm{SMP}} / \mathrm{gSSV}\right)$ as well as from phase 2 to phase $3\left(0.13 \mathrm{~g} \mathrm{COD}_{\mathrm{SMP}} / \mathrm{gSSV}\right)$. Such decrease might have occurred due to PAC's capability of minimizing the toxic effects and facilitating the biomass acclimation, which enhanced the bio-degradation of intermediate compounds produced throughout all operational phases. It is likely that PAC adsorbed sulfanilic acid and other toxic byproducts, thereby contributing to reduce toxicity and cell lysis. It is also possible that PAC had also adsorbed part of the produced SMPs, and this would probably favor
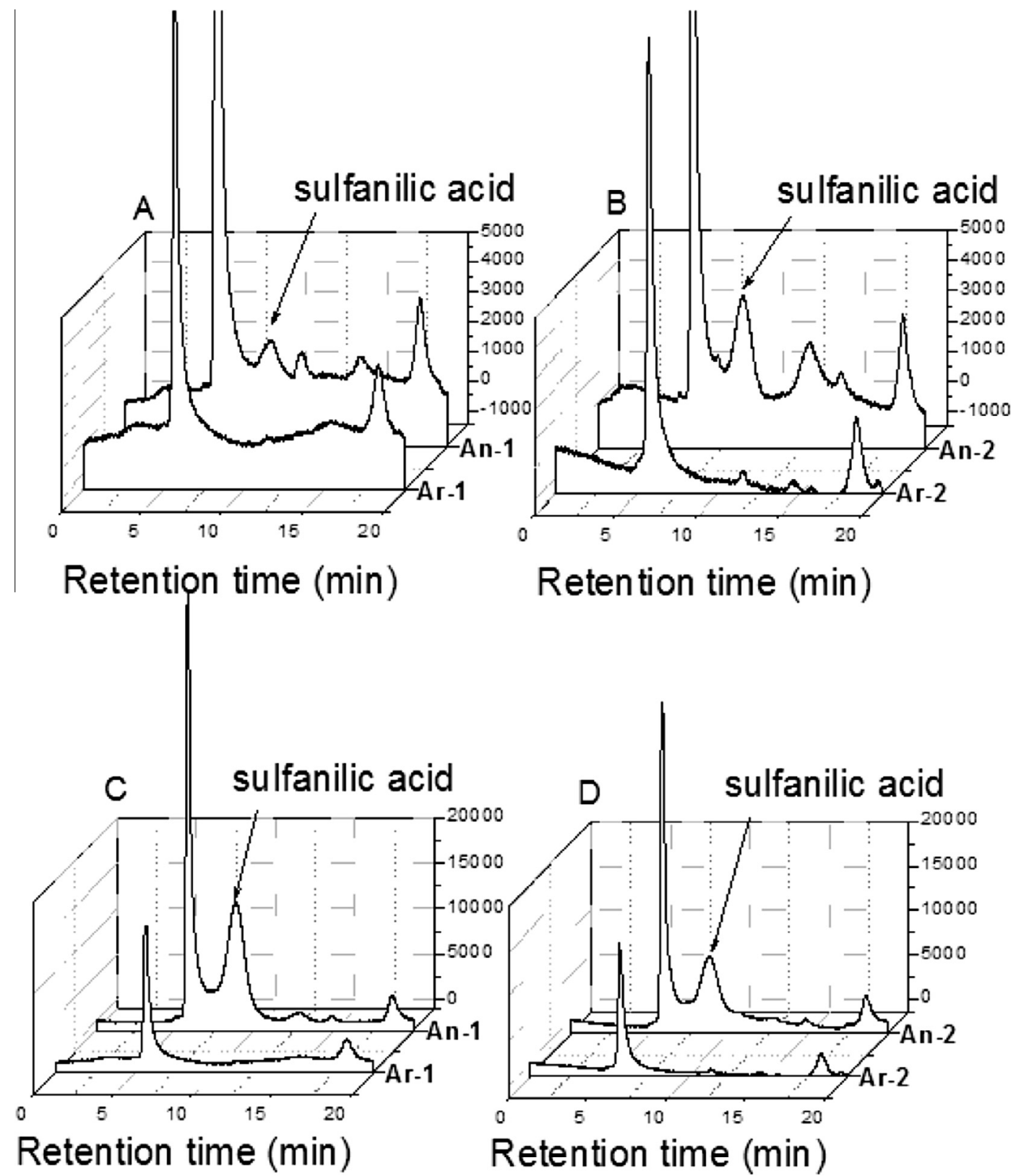

Retention time (min)

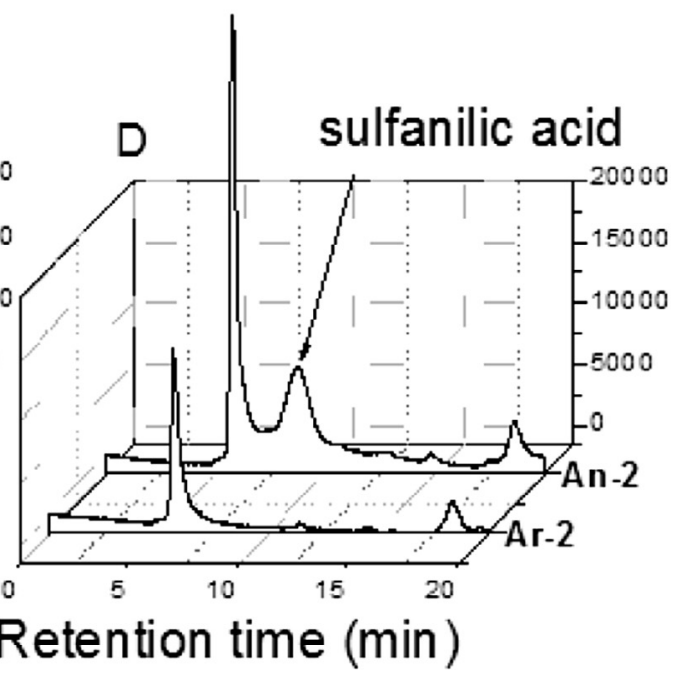

Fig. 10. Typical chromatogram of samples collected from the inside anaerobic and aerobic reactors in phases 2 (A and B) and 3 (C and D). 
its bio-degradation due to its increased permanence inside the reactor.

As far as the aerobic post-treatment is concerned, it can be assumed that the residual soluble COD is predominantly comprised of SMPs, since it was not observed, in any of the three operational phases, detectable amounts of VFA $\left(\mathrm{COD}_{\mathrm{VFA}}\right)$, sulfanilic acid (aromatic amines) and residual dye.

\subsection{Evaluation of aerobic post-treatment in the removal of residual azo dye and intermediate compounds}

According to some authors [31], the treatment of textile effluents must aim to simultaneously remove azo dye and mineralize the generated metabolites. Fig. 10 shows the color removal efficiencies in An1/Ar1 and An2/Ar2 systems. It can be seen that throughout operational phases 2 and 3 the efficiency of RGYRNL removal was significantly higher $(p$-value $<0.05)$ in the reactor An2 (80.6\% phase 2 and $90.4 \%$ phase 3 ) when compared to reactor An1 (78.2\% phase 2 and $86.1 \%$ phase 3 ). Such outcome was expected, since other studies performed by our research group also showed higher color removal in anaerobic reactors operated with PAC ( $4 \mathrm{~g} / \mathrm{L})$ when they were fed with synthetic and industrial effluents $[12,24]$.

Yet, it was possible to observe that the aerobic post-treatment was able to remove about $24 \%$ of color in reactor Ar1 during phase 2 and 34\% in phase 3. Such values were lower than those obtained in reactor $\operatorname{Ar} 2,35 \%$ in phase 2 and $40 \%$ in phase 3 . The lower color removal efficiency observed in the aerobic systems when compared to anaerobic reactors is due to the fact that azo bond $(-\mathrm{N}=\mathrm{N}-$ ) cleavage is difficult in oxidative environments. In addition, the dissolved oxygen outcompetes the azo dye as the preferred electron acceptor, thereby impairing the azo bond reduction. In other words, the decolorization of azo dyes is easier in reductive environments, in the absence of electron acceptors which have reduction potentials lower than the azo dye.

In regards to the degradation of byproducts (aromatic amines) generated by the azo dye's reductive degradation, Ar1 and Ar2 aerobic systems demonstrated an excellent performance in removing sulfanilic acids. As it can be seen in the chromatograms presented in Fig. 10, the peak of such compound, found in higher amount in samples from inside the anaerobic reactors in phases 2 and 3, was not detected in the effluent from both aerobic reactors (Ar1 and At2). This indicates the aerobic system was responsible for the total mineralization of this anaerobic byproduct. Other authors such as Chen et al. [32] have also demonstrated the capacity of activated sludge systems to completely remove sulfanilic acid. Therefore, the data presented here support the hypothesis that the aerobic phase is effective in polishing the effluent from anaerobic reactors treating azo dyes since they reduce the concentration of intermediate compounds and byproducts allegedly toxic to the environment.

As far as the removal of SMP in the aerobic step is concerned, the data gathered along the three operational phases shows that the $\mathrm{Ar}-1$ reactor was not efficient in removing $\mathrm{COD}_{\mathrm{SMP}}$. The $\mathrm{COD}_{\mathrm{SMP}}$ values in the final effluent in most phases were greater than the values observed in the effluent from An-1. On the other hand the $\mathrm{COD}_{\mathrm{SMP}}$ effluent from aerobic reactor Ar-2 was lower when compared to that observed in the anaerobic effluent (An-2) in all operational phases. A hypothesis to explain this behavior is the largest amount of toxic compounds that seemed to reach the reactor Ar-1 due to the lack of PAC.

The anaerobic-aerobic combined system turned out to be efficient for removing organic matter (VFA and aromatic amines) and color during the treatment of azo dye solutions. Other works involving the combined use of chemical and biological processes for the treatment of synthetic textile wastewater have been reported in the literature, with results less promising than the ones obtained in this study. For instance, Yasar et al. [33] investigated the use of anaerobic reactor combined with ozone oxidation. The results showed that higher doses of ozone ( $\left.1.25 \mathrm{mgO}_{3} / \mathrm{mgCOD}\right)$ to achieve color removal efficiencies higher than $50 \%$ and COD removal efficiencies greater than $90 \%$.

The results presented in this paper show that it is possible to achieve COD and color removal efficiency greater than $90 \%$ using the combined aerobic and anaerobic reactors. In addition, the use of this system in full scale would be facilitated since most textile industries employ the aerobic activated sludge system to treat their effluents.

\section{Conclusion}

- The anaerobic-aerobic combined system turned out to be efficient for removing organic matter and color during the treatment of model azo dye solutions. The An2/Ar2 system, in which the anaerobic reactor had PAC in its interior, exhibited organic matter and color removal efficiencies higher than those observed in the control system $(\operatorname{An} 1 / \operatorname{Ar} 1)$ in all operational phases.

- The presence of PAC inside the anaerobic reactor showed to be directly related to SMPs' dynamic production. Throughout the biomass acclimation phase (phase 1), it was observed a higher accumulation of $\mathrm{COD}_{\mathrm{SMP}}$ in the reactor operated with PAC (An2), when compared with the reactor without PAC (An1). In phases 2 and 3, in which the model azo dye was added, it was observed an increase in the $\mathrm{COD}_{\mathrm{SMP}}$ for reactor An1 (without PAC) in relation to phase 1 ; and a decrease in $\mathrm{COD}_{\mathrm{SMP}}$ for reactor An2. This indicates that PAC minimized the toxicity effects caused by the presence of some byproducts (ex: aromatic amines and VFA) and consequently decreased SMP production in these phases.

- The aerobic reactors were able to completely remove the sulfanilic acid (sulfonated aromatic amine) produced during the anaerobic degradation of the model azo dye, corroborating that systems combining anaerobic and aerobic reactors are a good technological alternative for the treatment of effluents containing azo dyes.

\section{Acknowledgments}

The authors would like to thank the financial support obtained from the following Brazilian institutions: CAPES, CNPq, FAPEMIG and UFOP.

\section{References}

[1] E. Acuner, F.B. Dilek, Treatment of tectilon yellow 2G by Chlorella vulgaris, Process Biochem. 39 (2004) 623-631.

[2] U. Aftab, M.R. Khan, M. Mahfooz, M. Ali, S.H. Aslam, A. Rehman, Decolourization and degradation of textile azo dyes by Corynebacterium sp. Isolated from industrial effluent, Pak. J. Zool. 43 (2011) 1-8.

[3] S. Sadri Moghaddam, M.R. Alavi Moghaddam, M. Arami, A comparison study on acid red 119 dye removal using two different types of waterworks sludge, Water Sci. Technol. 61 (2010) 1673-1681.

[4] S. Netpradit, P. Thiravetyan, S. Towprayoon, Application of 'waste' metal hydroxide sludge for adsorption of azo reactive dyes, Water Res. 37 (2003) $763-772$

[5] A. Kunz, V. Reginatto, N. Durán, Combined treatment of textile effluent using the sequence Phanerochaete chrysosporium-ozone, Chemosphere 44 (2001) $281-287$

[6] Y. Dong, J. Chen, C. Li, H. Zhu, Decoloration of three azo dyes in water by photocatalysis of $\mathrm{Fe}$ (III) oxalate complexes $/ \mathrm{H}_{2} \mathrm{O}_{2}$ in the presence of inorganic salts, Dyes Pigm. 73 (2007) 261-268.

[7] A. Pandey, P. Singh, L. Iyengar, Bacterial decolorization and degradation of azo dyes, Int. Biodeterior. Biodegrad. 59 (2007) 73-84. 
[8] S. Asad, M.A. Amoozegar, A.A. Pourbabaee, M.N. Sarbolouki, S.M.M. Dastgheib, Decolorization of textile azo dyes by newly isolated halophilic and halotolerant bacteria, Bioresour. Technol. 98 (2007) 2082-2088.

[9] J.A. Field, F.J. Cervantes, F.P. Van der Zee, G. Lettinga, Role of quinones in the biodegradation of priority pollutants: a review, Water Sci. Technol. 42 (2000) 215-222.

[10] F.P. Van der Zee, F.J. Cervantes, Impact and application of electron shuttles on the redox (bio)transformation of contaminants: a review, Biotechnol. Adv. 27 (2009) 256-277.

[11] F.J. Cervantes, A.B. Dos Santos, Reduction of azo dyes by anaerobic bacteria: microbiological and biochemical aspects, Rev. Environ. Sci. Biotechnol. 10 (2011) 125-137.

[12] B.E.L. Baêta, R.L. Ramos, D.R.S. Lima, S.F. Aquino, Use of submerged anaerobic membrane bioreactor (SAMBR) containing powdered activated carbon (PAC) for the treatment of textile effluents, Water Sci. Technol. 65 (2012) 15401547.

[13] A. Stolz, Basic and applied aspects in the microbial degradation of azo dyes, Appl. Microbiol. Biotechnol. 56 (2001) 69-80.

[14] M.E.R. Silva, P.I.M. Firmino, A.B. Dos Santos, Impact of the redox mediator sodium anthraquinone-2,6-disulphonate (AQDS) on the reductive decolourisation of the azo dye reactive red 2 (RR2) in one- and two-stage anaerobic systems, Bioresour. Technol. 121 (2012) 1-7.

[15] F.P. Van Der Zee, S. Villaverde, Combined anaerobic-aerobic treatment of azo dyes - a short review of bioreactor studies, Water Res. 39 (2005) 1425-1440.

[16] E.H. Koupaie, M.R. Moghaddam, S.H. Hashemi, Post-treatment of anaerobically degraded azo dye acid red 18 using aerobic moving bed biofilm process: enhanced removal of aromatic amines, J. Hazard. Mater. 195 (2011) 147-154.

[17] C. O’Neill, A. Lopez, S. Esteves, F.R. Hawkes, D.L. Hawkes, S. Wilcox, Azo-dye degradation in an anaerobic-aerobic treatment system operating on simulated textile effluent, Appl. Microbiol. Biotechnol. 53 (2000) 249-254.

[18] M.E.R. Silva, P.I.M. Firmino, M.R. Sousa, A.B. Dos Santos, Sequential anaerobic/ aerobic treatment of dye-containing wastewaters: colour and cod removals, and ecotoxicity tests, Appl. Biochem. Biotechnol. 166 (2012) 1057-1069.

[19] C.A.L. Chernicharo, Anaerobic Reactors: Biological Wastewater Treatment Series, first ed., IWA Publishing, London, 2007.

[20] M. Von Sperling, Activated Sludge and Aerobic Biofilm Reactors, first ed., IWA Publishing, London, 2007.

[21] P.L. Mesquita, G.S. Leite, R.J.C.F. Afonso, S.F. Aquino, Validation of a liquid chromatography methodology for the simultaneous determination of seven volatile fatty acids (VFA) intermediates of anaerobic digestion, Eng. Sanit. Amb. 18 (2013) 295-302.

[22] H.M. Pinheiro, E. Touraud, O. Thomas, Aromatic amines from azo dy reduction: status review with emphasis on direct UV spectrophotometric detection in textile industry wastewaters, Dyes Pigm. 61 (2004) 121-139.

[23] S.F. Aquino, C.A.L. Chernicharo, Acúmulo de ácidos graxos voláteis (AGVS) em reatores anaeróbios sob estresse: causa e estratégias de controle, Eng. Sanit Amb. 10 (2005) 152-161.

[24] B.E.L. Baêta, H.J. Luna, A.L. Sanson, S.Q. Silva, S.F. Aquino, Degradation of model azo dye in submerged anaerobic membrane bioreactor (SAMBR) operated with powdered activated carbon (PAC), J. Environ. Manage. 128 (2013) 462-470.

[25] S.F. Aquino, A.Y. Hu, A. Akram, D.C. Stuckey, Characterization of dissolved compounds in submerged anaerobic membrane bioreactors (SAMBRs), J. Chem. Technol. Biotechnol. 81 (2006) 1894-1904.

[26] S.F. Aquino, D.C. Stuckey, The effect of organic and hydraulic shock loads on the production of soluble microbial products (SMP) in anaerobic digesters Water Environ. Res. 76 (2004) 2628-2636.

27] A. Akram, D.C. Stuckey, Flux and performance improvement in a submerged anaerobic membrane bioreactor (SAMBR) using powdered activated carbon (PAC), Process Biochem. 43 (2008) 93-102.

[28] S.F. Aquino, D.C. Stuckey, Soluble microbial products (SMP) formation in anaerobic chemostats in the presence of toxic compounds, Water Res. 38 (2003) 255-266

[29] N. Yemashova, S. Kalyuzhny, Microbial conversion of selected azo dyes and their breakdown products, Water Sci. Technol. 53 (2006) (2006) 163-171.

[30] C.S. Laspidou, B.E. Rittmann, Modeling the development of biofilm density including active bacteria inert biomass and extracellular polymeric substances, Water Res. 38 (2004) 3349-3361.

[31] M. Hakimelahi, M.R.A. Moghaddam, S.H. Hashemi, Biological treatment of wastewater containing an azo dye using mixed culture on alternating anaerobic/aerobic sequencing batch reactors, Biotechnol Bioproc. E 17 (2012) 875-880.

[32] C. Gang, K.Y. Cheng, M.P. Ginige, A.H. Kaksonen, Aerobic degradation of sulfanilic acid using activated sludge, Water Res. 46 (2012) 145-151.

[33] A. Yasar, N. Ahmad, M.N. Chaudhry, M.S.U. Rehman, A.A.A. Khan, Ozone for color and COD removal of raw and anaerobically biotreated combined industrial wastewater, Pol. J. Environ. Stud. 16 (2007) 289-294. 